\title{
Risk and prognostic factors of breast cancer with liver metastases
}

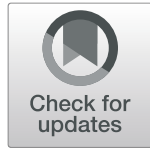

Lei $\mathrm{Ji}^{1,2+}$, Lei Cheng ${ }^{1,2+}$, Xiuzhi Zhu ${ }^{2,3}$, Yu Gao ${ }^{1,2}$, Lei Fan ${ }^{2,3^{*}}$ and Zhonghua Wang ${ }^{1,2,3^{*}}$ (D)

\begin{abstract}
Background: Liver metastasis is a significant adverse predictor of overall survival (OS) among breast cancer patients. The purpose of this study was to determine the risk and prognostic factors of breast cancer with liver metastases (BCLM).

Methods: Data on 311,573 breast cancer patients from the Surveillance, Epidemiology, and End Results (SEER) database and 1728 BCLM patients from Fudan University Shanghai Cancer Center (FUSCC) were included. Logistic regression was used to identify risk factors for liver metastasis. Cox proportional hazards regression model was adopted to determine independent prognostic factors in BCLM patients.

Results: Young age, invasive ductal carcinoma, higher pathological grade, and subtype of triple-negative and human epidermal growth factor receptor 2 positive (HER2+) were risk factors for developing liver metastasis. The median OS after liver metastasis was 20.0 months in the SEER database and 27.3 months in the FUSCC dataset. Molecular subtypes also played a critical role in the survival of BCLM patients. We observed that hormone receptorpositive (HR+)/HER2+ patients had the longest median OS (38.0 for SEER vs. 34.0 months for FUSCC), whereas triplenegative breast cancer had the shortest OS (9.0 vs. 15.6 months) in both SEER and FUSCC. According to the results from the FUSCC, the subtype of HR+/HER2+ (hazard ratio $(\mathrm{HR})=2.62 ; 95 \%$ confidence interval $(\mathrm{Cl})=1.88-3.66 ; P<$ $0.001)$ and $\mathrm{HR}-/ \mathrm{HER} 2+(\mathrm{HR}=3.43 ; 95 \% \mathrm{Cl}=2.28-5.15 ; P<0.001)$ were associated with a significantly increased death risk in comparison with HR+/HER2- patients if these patients did not receive HER2-targeted therapy. For those who underwent HER2-targeted therapy, however, HR+/HER2+ subtype reduced death risk compared with HR+/HER2subtype ( $\mathrm{HR}=0.74 ; 95 \% \mathrm{Cl}=0.58-0.95 ; P<0.001)$.
\end{abstract}

Conclusions: Breast cancer patients at a high risk for developing liver metastasis deserve more attention during the follow-up. BCLM patients with HR+/HER2+ subtype displayed the longest median survival than HR+/HER2- and triple-negative patients due to the introduction of HER2-targeted therapy and therefore it should be recommended for HER2+ BCLM patients.

Keywords: Breast cancer, Liver metastasis, Risk factors, Prognostic factors, HER2-targeted therapy

\footnotetext{
*Correspondence: teddyfl@163.com; zhonghuawang95@hotmail.com

${ }^{\dagger}$ Lei Ji and Lei Cheng contributed equally to this work.

2Department of Oncology, Shanghai Medical College, Fudan University,

Shanghai, China

'Department of Medical Oncology, Fudan University Shanghai Cancer

Center, Shanghai, China

Full list of author information is available at the end of the article
}

(c) The Author(s). 2021 Open Access This article is licensed under a Creative Commons Attribution 4.0 International License, which permits use, sharing, adaptation, distribution and reproduction in any medium or format, as long as you give appropriate credit to the original author(s) and the source, provide a link to the Creative Commons licence, and indicate if changes were made. The images or other third party material in this article are included in the article's Creative Commons licence, unless indicated otherwise in a credit line to the material. If material is not included in the article's Creative Commons licence and your intended use is not permitted by statutory regulation or exceeds the permitted use, you will need to obtain permission directly from the copyright holder. To view a copy of this licence, visit http://creativecommons.org/licenses/by/4.0/ The Creative Commons Public Domain Dedication waiver (http://creativecommons.org/publicdomain/zero/1.0/) applies to the data made available in this article, unless otherwise stated in a credit line to the data. 


\section{Background}

Breast cancer is the most frequently diagnosed cancer and is the second leading cause of cancer-related death among women in developed countries [1]. More than $5 \%$ of cases are metastatic disease at the time of diagnosis, while almost $30 \%$ of patients newly diagnosed with localized or regional disease will recur [2, 3]. Early breast cancer patients has a 5-year survival rate of more than $90 \%$, while it sharply decline to $26 \%$ for those with de novo metastatic breast cancer (MBC) [2]. Notably, the incidence of liver metastasis is only second to bone and lung metastasis, accounting for $71 \%$ of all patients in an autopsy study $[4,5]$. Moreover, liver metastasis could result in treatment resistance and higher mortality. Median survival for breast cancer with liver metastases (BCLM) was only 3-15 months, with a 5-year survival rate of only $8.5 \%[6,7]$. Because liver metastasis is an important factor influencing long-term survival of breast cancer patients, early identification may offer an opportunity for curative hepatic resection and prolonging the survival time [8]. However, routine screening for distant metastasis among patients without clinical signs and symptoms related to relapse is not recommended according to breast cancer follow-up or surveillance guidelines due to lack of demonstrated clinical benefits [9]. Thus, BCLM patients who usually present asymptomatically or with atypical symptoms tend to be ignored in the beginning stage of liver metastasis.

Several clinicopathological factors, especially molecular subtypes, can influence the occurrence and prognosis of liver metastasis. A study which included 3726 early breast cancer patients diagnosed from 1986 to 1992 showed that luminal/HER2 and HER2-enriched tumors were more susceptible to brain, liver, and lung metastases than luminal A tumors [10]. Dent et al. found that triple negative breast cancer had a higher risk of a visceral metastasis compared with other breast cancer subtypes [11]. Importantly, molecular subtypes are not only a risk factor for liver metastasis but also a predictor of clinical outcome of BCLM patients. A registry analysis of 500 BCLM patients found HR positive breast cancer reduced the risk of death by $33 \%$ compared with HR negative breast cancer [7]. A retrospective study of 145 BCLM patients also showed that estrogen receptor (ER) positive patients had a longer median than ER negative patients (7 vs 3.65 months) [12]. Additionally, multiple studies have shown that triple negative breast cancer has the worst prognosis among BCLM patients [13, 14]. There are some controversial or even contradicting results, however, regarding the prognostic value of molecular subtypes in BCLM patients. A previous study including 104 BCLM patients concluded that there was no impact of breast cancer subtypes on the survival after hepatic metastases [15]. A single center study of British population also presented similar results [16]. HER2 positive breast cancer is associated with a more aggressive phenotype and worse prognosis. In an earlier study, Kennecke et al. reported that $\mathrm{MBC}$ patients with luminal A subtype had longer survival than those with luminal/ HER2 subtype (2.2 vs 1.3 years) owing to the lack of effective targeted therapy [10]. However, HER2 positive $\mathrm{MBC}$ patients with the addition of trastuzumab had better prognosis than those with HER2 negative disease historically considered to have a relatively favorable prognosis [17]. A recent population-based study on de novo BCLM patients also observed that patients with HR+/HER2+ subtype exhibited the longest median survival time of 31 months, substantially better than those with HR+/HER2- subtype (21 months) and other subtypes [14].

These above studies including a relatively small sample size are largely based on retrospective data and performed at a single academic center, yielding these different or even contradicting results. Our study aimed to explore risk factors for liver metastases (LM) to identify breast cancer patients at a high risk of liver metastasis at initial diagnosis. In addition, we hoped to detect independent prognostic factors in BCLM patients based on population-based data from the SEER database and large sample size data from the FUSCC dataset. As a result, we were able to evaluate the consistency and difference of these prognostic factors in two different populations and investigate the reasons behind.

\section{Methods}

Within the SEER Research Data 1975-2016 dataset, breast cancer patients diagnosed from 2010 to 2016 were extracted [18]. Inclusion criteria were as follows: (a) age $\geq 18$ years; (b) histologically confirmed diseases; (c) known liver metastases status. The exclusion criteria were as follows: (a) carcinoma in situ; (b) multiple primary malignant tumors; (c) unknown follow-up or survival months of 0 month, including patients diagnosed via autopsy or a death certificate. Finally, there were 311, 573 breast cancer patients for further analysis, among whom there were 15,884 patients with de novo $\mathrm{MBC}$ at initial diagnosis (Fig. S1). Within the FUSCC dataset collected between 2007 and 2018, there were a total of 3453 female MBC patients. The diagnosis of liver metastases was based on the radiologic scan, the biopsy of metastatic lesions or the surgical resection specimens. Inclusion criteria were as follows: (a) age > 20 years; (b) histologically confirmed diseases; (c) developing liver metastases during the course of the disease; (d) detailed medical records. The exclusion criteria were as follows: (a) carcinoma in situ; (b) patients with bilateral breast cancer or other malignant diseases; (c) unknown followup. Ultimately, 1728 BCLM patients were eligible for 
subsequent analysis (Fig. S2). Among 626 HER2 positive BCLM patients, 528 patients with subsequent HER2targeted therapy information were enrolled to explore the effect of HER2-targeted therapy. Last follow-up was conducted on June 15, 2019, and the median follow-up time was 17.4 months (interquartile range [IQR], 8.5 to 31.0 months).

Incidence was defined as the number of BCLM patients divided by the total number of breast cancer patients or MBC patients in the SEER database. First liver metastases referred to liver metastases as the initial metastatic site, while subsequent liver metastases suggested that breast cancer cells gradually metastasized to the liver in the development of disease. Breast cancer subtypes were categorized as follows: HR-positive/ HER2-negative (HR+/HER2-); HR+/HER2+; HR -/HER2+; HR-/HER2- (triple-negative) and unknown. Variables in this study included demographic characteristics and clinicopathological factors such as histology, pathological grade, number of extrahepatic metastatic sites, treatment information and subtype. OS was calculated from the date of diagnosis of liver metastases to the date of death from any cause, and patients alive at the date of last follow-up were censored.

Multivariate logistic regression analyses were performed to determine the risk factors associated with the presence of liver metastases at initial diagnosis. Odds ratios (ORs) with 95\% confidence intervals (CIs) were also calculated. Univariate and multivariate Cox regression analyses were adopted to identify the prognostic factors associated with increased all-cause mortality. We also calculated HRs and 95\% CIs in the Cox regression model. The consistency and difference of these prognostic factors in two different populations was evaluated on the basis of the data from the SEER database and the FUSCC dataset, and then we attempted to explore the possible causes behind. The Kaplan-Meier method and a log-rank test were used to estimate survival and evaluate differences between survival curves. Statistical analyses were performed using $\mathrm{R}$ (version 3.5.1), and a twosided $P$-value less than 0.05 was considered statistically significant.

\section{Results}

\section{Baseline characteristics and the incidence of liver} metastases

A total of 311,573 patients from SEER database diagnosed between 2010 and 2016 were included in the present study. Of these patients, there were 15,884 MBC patients and 4067 BCLM patients at initial diagnosis (Table 1). In the FUSCC dataset, there were 1728 of 3048 metastatic breast cancer patients had liver metastases during the follow-up (Table 2). The consistent and inconsistent characteristics of two datasets were shown in Tables 1 and 2. The baseline characteristics showed a higher proportion of patients with infiltrating duct carcinoma ( $73.1 \%$ vs $80.8 \%)$, extrahepatic metastases $(73.9 \%$ vs $67.5 \%)$ and HR+/HER2 - subtype (39.6 44.3\%) in the both SEER and FUSCC dataset. However, the differences between SEER and FUSCC were significant as well, such age, race, stage at initial diagnosis. The patients in the FUSCC dataset were younger and almost all of them were Asian patients, different from those in the SERR database. Most notably, the majority of FUSCC patients (88.3\%) were recurrent breast cancer who underwent curative resection for primary tumors while all patients from the SEER database were diagnosed with de novo metastatic breast cancer.

As presented in Table S1, the 4067 BCLM patients accounted for $1.31 \%$ of the entire cohort and $25.6 \%$ of the MBC patients, including 1612 patients with $\mathrm{HR}+1$ HER2- subtype tumors (39.64\%), 884 with HR+/HER2+ tumors (21.74\%), 601 with HR-/HER2+ tumors (14.78\%), 544 with triple-negative tumors (13.38\%), and 426 with unknown tumors (10.47\%). The proportion of patients with HR-/HER2+ tumors ranked highest (4.27\% of the entire cohort and $44.13 \%$ of the metastatic subclass), while those with HR+/HER2- tumors ranked lowest proportion in both entire and metastatic patients ( $0.76 \%$ of the entire cohort and $19.34 \%$ of the metastatic subclass, Table S1). For patients from FUSCC, patients with first liver metastases attributed to $35.59 \%$ proportion of all MBC patients (Table S2).

\section{Risk factors for liver metastasis}

Using breast cancer patients aged between 18 and 40 as reference, the increase of age was associated with significant trend towards decreased risk of liver metastasis, with OR of $0.59,0.46$, and 0.46 for those aged between 41 and $60,61-80$ and those older than 80-years age, respectively $(P<0.001$ for all, Table 3$)$. The risk of liver metastasis was decreased in Hispanic ( $\mathrm{OR}=0.82,95 \%$ $\mathrm{CI}=0.74-0.91 ; P<0.001)$ and Asian or Pacific Islander patients $(\mathrm{OR}=0.81 ; 95 \% \mathrm{CI}=0.72-0.92 ; P=0.001)$, but was increased for black patients $(\mathrm{OR}=1.54 ; 95 \% \mathrm{CI}=$ 1.41-1.67; $P<0.001)$ in comparison with white patients. Married $(\mathrm{OR}=0.64 ; 95 \% \mathrm{CI}=0.60-0.68 ; P<0.001)$ and insured status $(\mathrm{OR}=0.53 ; 95 \% \mathrm{CI}=0.45-0.63 ; P<0.001)$ was associated with significantly decreased risk of liver metastasis when compared with the status of unmarried and uninsured, respectively. Compared with infiltrating duct carcinoma, lobular carcinoma $(\mathrm{OR}=0.68 ; 95 \% \mathrm{CI}=$ 0.59-0.77; $P<0.001)$ and the mix of infiltrating duct and lobular carcinoma $(\mathrm{OR}=0.66 ; 95 \% \mathrm{CI}=0.55-0.79 ; \quad P<$ 0.001 ) were both associated with decreased risk of liver metastasis. Tumors with higher pathological grade more inclined to metastasize to liver, in the comparison of grade II versus I $(\mathrm{OR}=3.89 ; 95 \% \mathrm{CI}=3.28-4.65 ; P<$ 
Table 1 Baseline characteristics of breast cancer with liver metastases at diagnosis in the SEER database

\begin{tabular}{|c|c|c|}
\hline \multirow[t]{2}{*}{ Variable } & \multicolumn{2}{|l|}{ Patients, No. \% } \\
\hline & Total $(n=311,573)$ & With Liver Metastases $(n=4067)$ \\
\hline \multicolumn{3}{|l|}{ Age, y } \\
\hline $18-40$ & $21,313(6.8 \%)$ & $494(12.1 \%)$ \\
\hline $41-60$ & $137,299(44.1 \%)$ & $1882(46.3 \%)$ \\
\hline $61-80$ & $129,497(41.6 \%)$ & $1414(34.8 \%)$ \\
\hline$>80$ & $23,464(7.5 \%)$ & $277(6.8 \%)$ \\
\hline \multicolumn{3}{|l|}{ Race } \\
\hline White & $207,400(66.6 \%)$ & $2565(63.1 \%)$ \\
\hline Black & $35,062(11.3 \%)$ & $737(18.1 \%)$ \\
\hline Hispanic & $37,499(12.0 \%)$ & $427(10.5 \%)$ \\
\hline Asian or Pacific Islander & 27,997 (9.0\%) & $305(7.5 \%)$ \\
\hline American Indian/Alaska Native & $1757(0.6 \%)$ & $23(0.6 \%)$ \\
\hline Unknown & $1858(0.6 \%)$ & $10(0.2 \%)$ \\
\hline \multicolumn{3}{|l|}{ Marital status } \\
\hline Unmarried $^{a}$ & $123,349(39.6 \%)$ & $2011(49.4 \%)$ \\
\hline Married & $171,728(55.1 \%)$ & $1827(44.9 \%)$ \\
\hline Unknown & $16,496(5.3 \%)$ & $229(5.6 \%)$ \\
\hline \multicolumn{3}{|l|}{ Insurance status } \\
\hline Uninsured ${ }^{\mathrm{b}}$ & $5417(1.7 \%)$ & $163(4.0 \%)$ \\
\hline Insured & $300,400(96.4 \%)$ & $3821(94.0 \%)$ \\
\hline Unknown & $5756(1.8 \%)$ & $83(2.0 \%)$ \\
\hline \multicolumn{3}{|l|}{ Histology } \\
\hline Infiltrating duct carcinoma & $234,958(75.4 \%)$ & $2971(73.1 \%)$ \\
\hline Lobular carcinoma & $27,050(8.7 \%)$ & $246(6.0 \%)$ \\
\hline Infiltrating duct and lobular carcinoma & $16,392(5.3 \%)$ & $133(3.3 \%)$ \\
\hline Other types ${ }^{c}$ & $33,173(10.6 \%)$ & $717(17.6 \%)$ \\
\hline \multicolumn{3}{|l|}{ Pathological Grade } \\
\hline । & $66,365(21.3 \%)$ & $144(3.5 \%)$ \\
\hline$\|$ & $129,786(41.6 \%)$ & $1147(28.2 \%)$ \\
\hline III/IV & $98,850(31.7 \%)$ & 1939 (47.7\%) \\
\hline Unknown & $16,572(5.3 \%)$ & $837(20.6 \%)$ \\
\hline \multicolumn{3}{|l|}{ Surgery of primary site } \\
\hline Yes & $285,989(91.8 \%)$ & $952(23.4 \%)$ \\
\hline No & $22,831(7.3 \%)$ & $3052(75.0 \%)$ \\
\hline Unknown & $2753(0.9 \%)$ & $63(1.5 \%)$ \\
\hline \multicolumn{3}{|l|}{ Radiotherapy } \\
\hline Yes & $162,703(52.2 \%)$ & $1082(26.6 \%)$ \\
\hline No/Unknown & $148,870(47.8)$ & 2985 (73.4\%) \\
\hline \multicolumn{3}{|l|}{ Chemotherapy } \\
\hline Yes & $130,572(42.0 \%)$ & $2802(68.9 \%)$ \\
\hline No/Unknown & $181,001(58.1 \%)$ & $1265(31.1 \%)$ \\
\hline \multicolumn{3}{|c|}{ Extrahepatic metastatic sites to lung, brain and bone, No } \\
\hline 0 & 298,407 (95.8\%) & $1060(26.1 \%)$ \\
\hline 1 & 9408 (3.0\%) & 1696 (41.7\%) \\
\hline
\end{tabular}


Table 1 Baseline characteristics of breast cancer with liver metastases at diagnosis in the SEER database (Continued)

\begin{tabular}{lll}
\hline Variable & Patients, No. $\%$ & With Liver Metastases $(\boldsymbol{n}=\mathbf{4 0 6 7 )}$ \\
\cline { 2 - 3 } & Total $(\boldsymbol{n}=\mathbf{3 1 1 , 5 7 3 )}$ & $891(21.9 \%)$ \\
\hline 2 & $2747(0.9 \%)$ & $177(4.4 \%)$ \\
All 3 & $343(0.1 \%)$ & $243(6.0 \%)$ \\
Unknown & $668(0.2 \%)$ & $1612(39.6 \%)$ \\
Subtype & & $884(21.7 \%)$ \\
HR+/HER2- & $211,127(67.8 \%)$ & $601(14.8 \%)$ \\
HR+/HER2+ & $32,962(10.6 \%)$ & $544(13.4 \%)$ \\
HR-/HER2+ & $14,089(4.5 \%)$ & $426(10.5 \%)$ \\
Triple-negative & $33,352(10.7 \%)$ & $20,043(6.4 \%)$ \\
Unknown & &
\end{tabular}

Notes: ${ }^{a}$ including divorced, separated, single (never married), and widowed; ${ }^{b}$ including insured, Insured/No specifics Any Medicaid; ${ }^{c}$ including other histology of invasive breast cancer except Infiltrating duct carcinoma, Lobular carcinoma and Infiltrating duct and lobular carcinoma; + denotes positive; - denotes negative; * denotes a statistically significant $P$-value; HER2 Human epidermal growth factor receptor $2, H R$ Hormone receptor, OR Odds ratio, $C l$ Confidence interval

$0.001)$ and grade $\mathrm{III} / \mathrm{IV}$ versus $\mathrm{I}(\mathrm{OR}=8.59 ; 95 \% \mathrm{CI}=$ $7.26-10.23 ; P<0.001)$. The analysis on molecular subtype indicated that $\mathrm{HR}+/ \mathrm{HER} 2+(\mathrm{OR}=3.13 ; 95 \% \mathrm{CI}=$ 2.87-3.41; $P<0.001), \mathrm{HR}-/ \mathrm{HER} 2+(\mathrm{OR}=4.75 ; 95 \% \mathrm{CI}=$ 4.30-5.25; $P<0.001$ ), and triple-negative subtypes (OR $=$ 1.92; $95 \% \mathrm{CI}=1.73-2.12 ; P<0.001)$ were all predictors for increased risk of liver metastasis in comparison with HR+/HER2- subtype, indicating the important role in disease progression played by HER2 status.

\section{Survival and prognostic factors}

Median survival among BCLM patients, as stratified by subtype, is displayed in Tables S1 and S2. The median survival among the entire cohort was 20.00 months in the SEER database (vs 27.30 months in the FUSCC dataset), with patients with the HR+/HER2+ subtype experiencing the longest median survival (38.00 vs 34.00 months) and patients with the triple-negative subtype experiencing the shortest median survival (9.00 vs 15.63 months) in the two cohorts. Additionally, breast cancer patients with first liver metastases showed distinctly longer survival times than those patients with subsequent liver metastases when the time was calculated from the diagnosis of liver metastasis (33.80 vs 17.47 months, Fig. 2a). However, patients with liver metastases had a shorter survival time than breast cancer patients developing liver metastases during the subsequent disease course when the time was calculated from the diagnosis of $\mathrm{MBC}$ (42.57 vs 33.80 months, Fig. 2b). The overall survival of all BCLM patients and the overall survival stratified by subtype or extent of extrahepatic metastatic disease are graphically displayed in Fig. 1.

Multivariate Cox proportional hazards models were used to assess the prognostic factors of patients with BCLM in the SEER database (Table 4) and the FUSSCC dataset was used for further exploration (Table 5). In the SEER database, older patients had worse survival, with a
HR of $1.39,1.84$ and 3.62 for patients aged 41-60, 6180 , and $>80$ years in comparison with those aged $18-40$ years $(P<0.001$ for all). Moreover, black and Hispanic race were associated with increased death risk compared with white race, with a HR of $1.35(P<0.001)$ and 1.16 $(P=0.028)$, respectively). Results also showed a prolonged survival in presence of the status of married and insurance $(\mathrm{HR}=0.84$ for married vs. unmarred, and 0.71 for insured vs. uninsured, with $P<0.001$ for all). For the survival comparisons among clinical factors, we found that increased pathological grade, treatment without chemotherapy and surgery of primary site, increased number of extrahepatic metastatic sites and triplenegative pathological type were all associated with poor prognosis. Specifically, compared with grade I disease, the HR was $1.35(P=0.013)$ for grade II and 1.69 for grade III-IV $(P<0.001)$, respectively. Treatment without surgery of primary site and chemotherapy generated a HR of 1.52 and 1.63, respectively compared with those received the treatments $(P<0.001$ for all). As expected, the HR increased from 1.42 to 3.43 as number of extrahepatic sites increased from 1 to 3 , compared with no extrahepatic metastasis $(P<0.001$ for all). In line of most previous studies, triple-negative subtype remained the deadliest type of cancer, with HR of 2.46 in comparison with $\mathrm{HR}+/$ HER2- cancers $(P<0.001)$. Interestingly, compared with $\mathrm{HR}+/ \mathrm{HER} 2$ - subtype, we observed that HER2+ might decrease the death risk in the SEER database, with $\mathrm{HR}$ of 0.69 for $\mathrm{HR}+/ \mathrm{HER} 2+(P<0.001)$ and $0.85(P=0.014)$ for HR-/HER2+ subtype, probably due to the introduction of HER2-targeted therapy.

Despite the substantial differences in baseline characteristics, the significant association of older age and greater number of extrahepatic metastasis sites with worse prognosis of the BCLM patients was also successfully observed in FUSCC datasets, similar to the former observation in the SEER database (Table 5). Additionally, 
Table 2 Baseline characteristics of breast cancer patients with liver metastases in the FUSCC dataset

\begin{tabular}{|c|c|}
\hline \multirow[t]{2}{*}{ Variable } & \multirow{2}{*}{$\begin{array}{l}\text { Patients, No. } \% \\
\text { Patients ( } n=1728)\end{array}$} \\
\hline & \\
\hline \multicolumn{2}{|l|}{ Age at diagnosis, y } \\
\hline $21-40$ & $288(16.7 \%)$ \\
\hline $41-60$ & $1143(66.1 \%)$ \\
\hline$>60$ & $297(17.2 \%)$ \\
\hline \multicolumn{2}{|l|}{ Histology } \\
\hline Infiltrating duct carcinoma & $1396(80.8 \%)$ \\
\hline Lobular carcinoma & $31(1.8 \%)$ \\
\hline Other & $301(17.4 \%)$ \\
\hline \multicolumn{2}{|l|}{ De novo metastatic diseases } \\
\hline No & $1526(88.3 \%)$ \\
\hline Yes & $202(11.7 \%)$ \\
\hline \multicolumn{2}{|l|}{ Surgery of primary site } \\
\hline No & $219(12.7 \%)$ \\
\hline Yes & $1509(87.3 \%)$ \\
\hline \multicolumn{2}{|l|}{ Prior Chemotherapy } \\
\hline No & $226(13.1 \%)$ \\
\hline Yes & $1502(86.9 \%)$ \\
\hline \multicolumn{2}{|l|}{ Prior Radiotherapy } \\
\hline No & 848 (49.1\%) \\
\hline Yes & 785 (45.4\%) \\
\hline Unknown & $95(5.5 \%)$ \\
\hline \multicolumn{2}{|l|}{ Recurrent sequence } \\
\hline First liver metastases & $1087(62.9 \%)$ \\
\hline Subsequent liver metastases & $641(37.1 \%)$ \\
\hline \multicolumn{2}{|c|}{ Extrahepatic metastatic sites to lung, brain, bone and lymph nodes, No } \\
\hline 0 & $561(32.5 \%)$ \\
\hline 1 & $534(30.9 \%)$ \\
\hline 2 & $382(22.1 \%)$ \\
\hline 3 & $223(12.9 \%)$ \\
\hline All 4 & $28(1.6 \%)$ \\
\hline \multicolumn{2}{|l|}{ Subtype } \\
\hline HR+/HER2- & 767 (44.3\%) \\
\hline $\mathrm{HR}+/ \mathrm{HER} 2+$ & $305(17.7 \%)$ \\
\hline HR-/HER2+ & $321(18.6 \%)$ \\
\hline Triple-negative & $270(15.6 \%)$ \\
\hline Unknown & $65(3.8 \%)$ \\
\hline
\end{tabular}

Notes: + denotes positive; - denotes negative; ${ }^{*}$ denotes a statistically significant $P$-value; HER2, human epidermal growth factor receptor 2; HR, hormone receptor

histological type exerted no effect on the prognosis and patients with triple negative BCLM had the worst survival in both SEER and FUSCC dataset. Notably, specific results were obtained due to data availability in two different populations, such as race, marital and insurance status, pathological grade and recurrent sequence. However, no significant difference was observed between survival of HER2+ patients with HR+/HER2- patients $(P>$ 0.05) in FUSCC dataset different from the result of SEER database, probably owing to difference in clinical application of HE2-targeted therapies.

\section{HER2-targeted therapy}

Owing to inconsistent results in the terms of the prognostic influence of molecular subtype in BCLM patients, we next explored whether HER2-targeted therapy leaded to these results. According to the results from the FUSCC, we found that in patients who did not receive HER-2 targeted therapy after liver metastases, HER2+ patients had an unfavorable prognosis compared with HR+/HER2- patients, with HR of 2.62 for $\mathrm{HR}+/ \mathrm{HER} 2+$ and 3.43 for HR-/HER2+ patients $(P<0.001$ for all, Table 6). However, HR+/HER2+ patients had a better prognosis than HR+/HER2- patients in patients who underwent HER2-targeted therapy after liver metastasis, with HR of $0.74(P<0.001)$. Unfortunately, we only observed an insignificant trend towards decreased death risk induced by HER2-targeted therapy for HR-/HER2+ patients compared with HR+/HER2- patients, with a HR of $0.81(P=0.110)$. Overall survival among BCLM patients with or without HER2-targeted therapy stratified by subtype were visualized in Fig. 2 .

\section{Discussion}

The risk factors for liver metastasis and prognostic factors of BCLM patients was described in this study. It was reported that the incidence of liver as the first metastatic site varied from $17.8-35 \%[7,19,20]$. We found that the incidence of first liver metastases was $25.6 \%$ in the SEER database and $35.59 \%$ in the FUSCC database, similar to these previous studies.

In addition to multiple molecular mechanisms underlying liver metastasis in breast cancer patients, a positive correlation between the occurrence of liver metastasis and multiple clinicopathological features, such as young age, invasive ductal carcinoma, higher pathological grade, and subtype of HER2+, was found in our study. The risk for liver metastasis surprisingly decreased with increasing age, which may result from a decrease in tumor-proliferative factors or deterioration of the immune system among patients of advanced age [21, 22] Zengel et al. found that invasive lobular carcinoma and mixed-type tumors had a higher incidence of bone metastasis than invasive ductal carcinoma, suggesting the potential role of histological type in the development of liver metastasis of breast cancer [23]. Infiltrating duct carcinoma was also found to be strongly associated with the occurrence of liver metastasis in our study. 
Table 3 Multivariate Logistic Regression for the risk factors of liver metastases at initial diagnosis of breast Cancer in the SEER database

\begin{tabular}{|c|c|c|}
\hline \multirow[t]{3}{*}{ Variable } & \multicolumn{2}{|l|}{ Among Entire Cohort } \\
\hline & \multicolumn{2}{|l|}{ Multivariate } \\
\hline & OR $(95 \% \mathrm{Cl})$ & $P$ Value \\
\hline \multicolumn{3}{|l|}{ Age at diagnosis, y } \\
\hline $18-40$ & 1 [Reference] & \\
\hline $41-60$ & $0.59(0.54-0.66)$ & $<0.001^{*}$ \\
\hline $61-80$ & $0.46(0.41-0.51)$ & $<0.001^{*}$ \\
\hline$>80$ & $0.46(0.40-0.54)$ & $<0.001^{*}$ \\
\hline \multicolumn{3}{|l|}{ Race } \\
\hline White & 1 [Reference] & \\
\hline Black & $1.54(1.41-1.67)$ & $<0.001^{*}$ \\
\hline Hispanic & $0.82(0.74-0.91)$ & $<0.001^{*}$ \\
\hline Asian or Pacific Islander & $0.81(0.72-0.92)$ & $0.001^{*}$ \\
\hline American Indian/Alaska Native & $0.93(0.59-1.38)$ & 0.725 \\
\hline Unknown & $0.38(0.19-0.68)$ & $<0.001^{*}$ \\
\hline \multicolumn{3}{|l|}{ Marital status } \\
\hline Unmarried $^{a}$ & 1[Reference] & \\
\hline Married & $0.64(0.60-0.68)$ & $<0.001^{*}$ \\
\hline Unknown & $0.83(0.72-0.96)$ & $0.013^{*}$ \\
\hline \multicolumn{3}{|l|}{ Insurance status } \\
\hline Uninsured $^{\mathrm{b}}$ & 1 [Reference] & \\
\hline Insured & $0.53(0.45-0.63)$ & $<0.001^{*}$ \\
\hline Unknown & $0.48(0.35-0.67)$ & $<0.001^{*}$ \\
\hline \multicolumn{3}{|l|}{ Histology } \\
\hline Infiltrating duct carcinoma & 1 [Reference] & \\
\hline Lobular carcinoma & $0.68(0.59-0.77)$ & $<0.001^{*}$ \\
\hline Infiltrating duct and lobular carcinoma & $0.66(0.55-0.79)$ & $<0.001^{*}$ \\
\hline Other types ${ }^{c}$ & $1.25(1.14-1.37)$ & $<0.001^{*}$ \\
\hline \multicolumn{3}{|l|}{ Pathological Grade } \\
\hline I & 1[Reference] & \\
\hline$\|$ & $3.89(3.28-4.65)$ & $<0.001^{*}$ \\
\hline III/IV & $8.59(7.26-10.23)$ & $<0.001^{*}$ \\
\hline Unknown & $20.75(17.32-25.02)$ & $<0.001^{*}$ \\
\hline \multicolumn{3}{|c|}{ Extrahepatic metastatic sites to lung, brain and bone, No } \\
\hline 0 & 1 [Reference] & \\
\hline 1 & $58.49(53.84-63.57)$ & $<0.001^{*}$ \\
\hline 2 & $123.15(110.89-136.76)$ & $<0.001^{*}$ \\
\hline All 3 & $246.17(195.34-310.33)$ & $<0.001^{*}$ \\
\hline Unknown & $299.10(240.01-372.94)$ & $<0.001^{*}$ \\
\hline \multicolumn{3}{|l|}{ Subtype } \\
\hline HR+/HER2- & 1 [Reference] & \\
\hline HR+/HER2+ & $3.13(2.87-3.41)$ & $<0.001^{*}$ \\
\hline HR-/HER2+ & $4.75(4.30-5.25)$ & $<0.001^{*}$ \\
\hline Triple-negative & $1.92(1.73-2.12)$ & $<0.001^{*}$ \\
\hline
\end{tabular}


Table 3 Multivariate Logistic Regression for the risk factors of liver metastases at initial diagnosis of breast Cancer in the SEER database (Continued)

\begin{tabular}{|c|c|c|}
\hline \multirow[t]{3}{*}{ Variable } & \multicolumn{2}{|c|}{ Among Entire Cohort } \\
\hline & \multicolumn{2}{|l|}{ Multivariate } \\
\hline & OR $(95 \% \mathrm{Cl})$ & $P$ Value \\
\hline Unknown & $1.48(1.31-1.68)$ & $<0.001^{*}$ \\
\hline
\end{tabular}

Purushotham et al. demonstrated that the higher the histological grade of the breast cancer, the higher the risk of developing visceral metastasis because high histological grade also correlated positively with proliferation and metastasis capacity of tumor cells [22]. In addition, our present results also confirmed that HER2-positive or triple-negative subtype had significantly greater odds of developing liver metastases than HR+/HER2- subtype, consistent with previously published studies focused on the metastatic pattern of different breast cancer subtype $[10,19,20,22]$. HER2 could upregulate the expression of the chemokine receptor CXCR4 and therefore promoted liver metastasis via the CXCL12/CXCR4 pathway, while elevated expression of the fibroblast growth factor homologous factor (FGF13) could mediate the formation of liver metastases in the triple negative breast cancer, resulting in molecular subtype-based liver metastasis of breast cancer [24-26]. A recent study reported the first discovery of the functional role of the DNA of neutrophil extracellular traps (NETs) in promoting breast cancer liver metastasis, a mechanism distinct from previous studies on cytokines and chemokine receptors, integrin complexes, metabolic program and proliferation signaling $[27,28]$. Early detection of liver metastases seemed to confer better outcomes of specific patients due to more effective treatments and better tolerance [29-34]. However, guidelines have reiterated that routine laboratory and imaging examination may not be applicable for patients with early breast cancer in the absence of signs or symptoms of metastatic disease because these

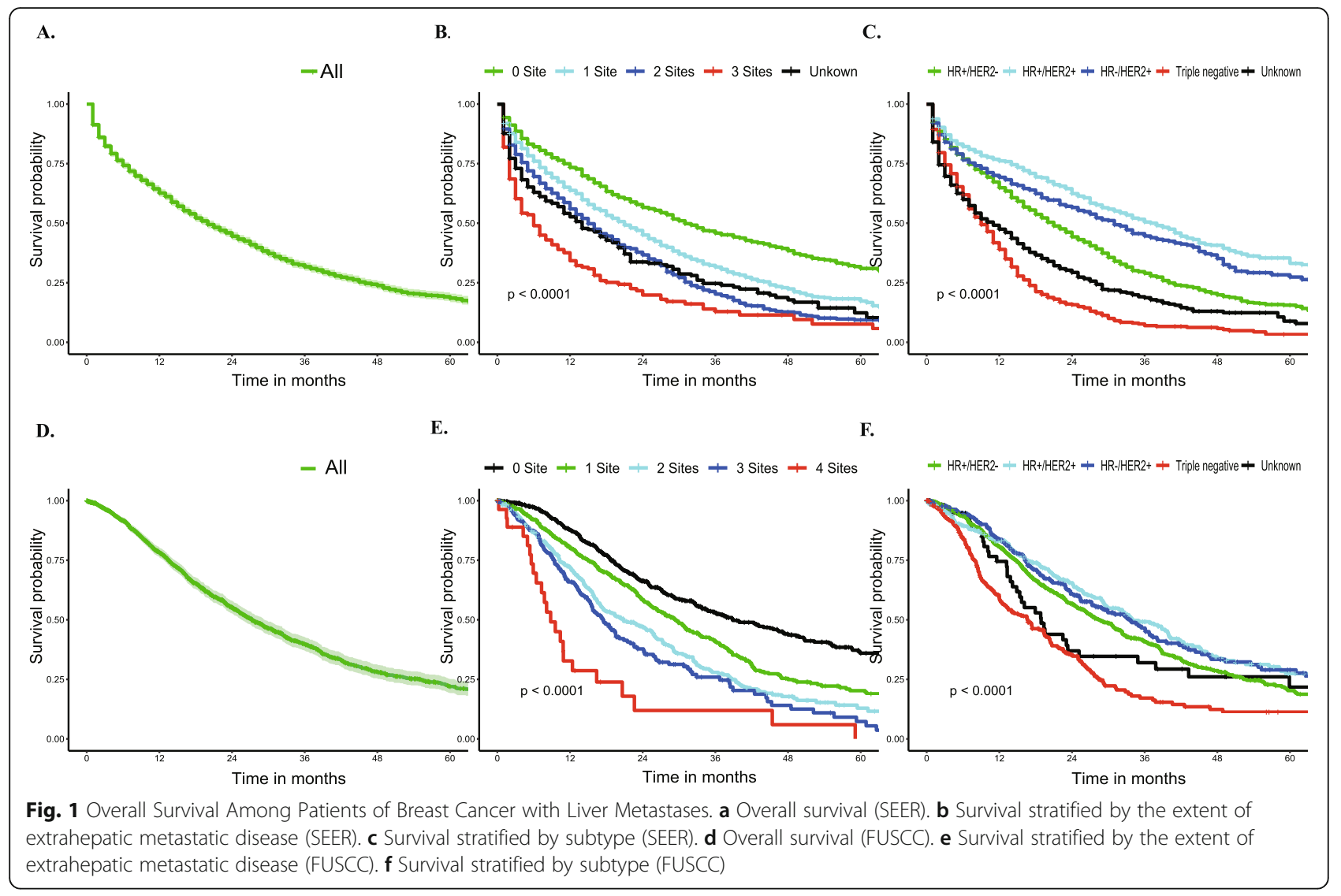


Table 4 Univariate and Multivariate Cox Regression for OS of breast cancer with liver metastases at diagnosis in the SEER database

\begin{tabular}{|c|c|c|c|c|}
\hline \multirow[t]{3}{*}{ Variable } & \multicolumn{4}{|l|}{ Overall Survival } \\
\hline & \multicolumn{2}{|l|}{ Univariable } & \multicolumn{2}{|l|}{ Multivariable } \\
\hline & $\mathrm{HR}(95 \% \mathrm{Cl})$ & $P$ Value & $\mathrm{HR}(95 \% \mathrm{Cl})$ & $P$ Value \\
\hline \multicolumn{5}{|l|}{ Age, y } \\
\hline $18-40$ & 1 [Reference] & & 1 [Reference] & \\
\hline $41-60$ & $1.52(1.32-1.76)$ & $<0.001^{*}$ & $1.39(1.20-1.61)$ & $<0.001^{*}$ \\
\hline $61-80$ & $2.17(1.88-2.51)$ & $<0.001^{*}$ & $1.84(1.58-2.15)$ & $<0.001^{*}$ \\
\hline$>80$ & $4.44(3.65-5.39)$ & $<0.001^{*}$ & $3.62(2.76-4.74)$ & $<0.001^{*}$ \\
\hline \multicolumn{5}{|l|}{ Race $^{a}$} \\
\hline White & 1 [Reference] & & 1 [Reference] & \\
\hline Black & $1.21(1.09-1.33)$ & $<0.001^{*}$ & $1.35(1.22-1.50)$ & $<0.001^{*}$ \\
\hline Hispanic & $0.99(0.87-1.13)$ & 0.895 & $1.16(1.02-1.32)$ & $0.028^{*}$ \\
\hline Asian or Pacific Islander & $0.86(0.74-1.02)$ & 0.078 & $0.90(0.76-1.05)$ & 0.182 \\
\hline American Indian or Alaska Native & $0.96(0.58-1.59)$ & 0.869 & $1.01(0.60-1.68)$ & 0.984 \\
\hline Unknown & $0.34(0.09-1.37)$ & 0.129 & $0.28(0.07-1.15)$ & 0.078 \\
\hline \multicolumn{5}{|l|}{ Marital status } \\
\hline Unmarried $^{\mathrm{a}}$ & 1[Reference] & & 1[Reference] & \\
\hline Married & $0.75(0.70-0.82)$ & $<0.001^{*}$ & $0.84(0.77-0.91)$ & $<0.001^{*}$ \\
\hline Unknown & $0.96(0.81-1.14)$ & 0.664 & $0.89(0.75-1.06)$ & 0.200 \\
\hline \multicolumn{5}{|l|}{ Insurance status } \\
\hline Uninsured $^{\mathrm{b}}$ & 1 [Reference] & & $1[$ Reference] & \\
\hline Insured & $0.75(0.62-0.91)$ & $0.003^{*}$ & $0.71(0.59-0.86)$ & $<0.001^{*}$ \\
\hline Unknown & $0.94(0.68-1.30)$ & 0.717 & $0.83(0.57-1.22)$ & 0.348 \\
\hline \multicolumn{5}{|l|}{ Histology } \\
\hline Infiltrating duct carcinoma & 1 [Reference] & & $1[$ Reference] & \\
\hline Lobular carcinoma & $1.14(0.97-1.34)$ & 0.112 & $0.87(0.74-1.03)$ & 0.101 \\
\hline Infiltrating duct and lobular carcinoma & $0.94(0.68-1.30)$ & 0.717 & $0.89(0.70-1.13)$ & 0.323 \\
\hline Other types ${ }^{c}$ & $1.43(1.30-1.58)$ & $<0.001^{*}$ & $1.18(1.05-1.33)$ & $0.005^{*}$ \\
\hline \multicolumn{5}{|l|}{ Pathological Grade } \\
\hline 1 & 1 [Reference] & & 1 [Reference] & \\
\hline$\|$ & $1.08(0.86-1.37)$ & 0.515 & $1.35(1.07-1.72)$ & $0.013^{*}$ \\
\hline III/IV & $1.30(1.04-1.64)$ & $0.022^{*}$ & $1.69(1.34-2.14)$ & $<0.001^{*}$ \\
\hline Unknown & $1.59(1.26-1.01)$ & $<0.001^{*}$ & $1.59(1.23-2.05)$ & $<0.001^{*}$ \\
\hline \multicolumn{5}{|l|}{ Surgery of primary site } \\
\hline Yes & 1 [Reference] & & 1 [Reference] & \\
\hline No & $1.72(1.56-1.89)$ & $<0.001^{*}$ & $1.52(1.38-1.68)$ & $<0.001^{*}$ \\
\hline Unknown & $0.93(0.62-1.38)$ & $<0.001^{*}$ & $0.96(0.64-1.43)$ & $<0.001^{*}$ \\
\hline \multicolumn{5}{|l|}{ Radiotherapy } \\
\hline Yes & 1 [Reference] & & $1[$ Reference] & \\
\hline No/Unknown & $1.03(0.94-1.12)$ & 0.528 & $0.95(0.87-1.04)$ & 0.270 \\
\hline \multicolumn{5}{|l|}{ Chemotherapy } \\
\hline Yes & 1 [Reference] & & $1[$ Reference] & \\
\hline No/Unknown & $2.03(1.87-2.20)$ & $<0.001^{*}$ & $1.63(1.50-1.78)$ & $<0.001^{*}$ \\
\hline \multicolumn{5}{|c|}{ Extrahepatic metastatic sites to lung, brain and bone, No } \\
\hline 0 & 1 [Reference] & & 1[Reference] & \\
\hline
\end{tabular}


Table 4 Univariate and Multivariate Cox Regression for OS of breast cancer with liver metastases at diagnosis in the SEER database (Continued)

\begin{tabular}{|c|c|c|c|c|}
\hline \multirow[t]{3}{*}{ Variable } & \multicolumn{4}{|l|}{ Overall Survival } \\
\hline & \multicolumn{2}{|l|}{ Univariable } & \multicolumn{2}{|l|}{ Multivariable } \\
\hline & HR (95\% Cl) & $P$ Value & HR (95\% CI) & $P$ Value \\
\hline 1 & $1.49(1.34-1.65)$ & $<0.001^{*}$ & $1.42(1.28-1.58)$ & $<0.001^{*}$ \\
\hline 2 & $1.94(1.73-2.18)$ & $<0.001^{*}$ & 1.85 (1.65-2.09) & $<0.001^{*}$ \\
\hline All 3 & $2.94(2.44-3.56)$ & $<0.001^{*}$ & $3.43(2.77-4.26)$ & $<0.001^{*}$ \\
\hline Unknown & $1.92(1.62-2.28)$ & $<0.001^{*}$ & $1.62(1.36-1.93)$ & $<0.001^{*}$ \\
\hline \multicolumn{5}{|l|}{ Subtype } \\
\hline $\mathrm{HR}+/ \mathrm{HER} 2-$ & 1 [Reference] & & 1 [Reference] & \\
\hline $\mathrm{HR}+/ \mathrm{HER} 2+$ & $0.59(0.53-0.66)$ & $<0.001^{*}$ & $0.69(0.61-0.77)$ & $<0.001^{*}$ \\
\hline HR-/HER2+ & $0.72(0.63-0.82)$ & $<0.001^{*}$ & $0.85(0.74-0.97)$ & $0.014^{*}$ \\
\hline Triple-negative & $2.10(1.88-2.35)$ & $<0.001^{*}$ & $2.46(2.18-2.77)$ & $<0.001^{*}$ \\
\hline Unknown & $1.54(1.36-1.74)$ & $<0.001^{*}$ & $1.38(1.20-1.58)$ & $<0.001^{*}$ \\
\hline
\end{tabular}

Notes: ${ }^{a}$ including divorced, separated, single (never married), and widowed; ${ }^{b}$ including insured, Insured/No specifics Any Medicaid; ${ }^{c}$ including other histology of invasive breast cancer except Infiltrating duct carcinoma, Lobular carcinoma and Infiltrating duct and lobular carcinoma;

+ denotes positive; - denotes negative; * denotes a statistically significant $P$-value; HER2 Human epidermal growth factor receptor 2, HR Hormone receptor, $O R$ Odds ratio, $\mathrm{Cl}$ Confidence interval

examinations may not bring more survival benefits [3537]. Our results can help to identify breast cancer patients at high risk for developing liver metastasis.

The median survival after liver metastasis was 20.00 months in the SEER database (vs 27.30 months in the FUSCC dataset) and varied significantly by molecular subtype. In both SEER database and FUSCC dataset, HR+/HER2+ patients had the longest survival (38.00 vs 34.00 months), whereas triple negative breast cancer had the worst prognosis ( 9.00 vs 15.63 months). Both $\mathrm{HR}+$ / HER2 + and HR-/HER2 + BCLM patients had a more favorable outcome than HR+/HER2-BCLM patients in the SEER database, but there was no significant difference in the FUSCC dataset. We hypothesized that it may originate from disparities in the application of HER2-targeted therapy. According to the results from FUSCC, HER2 positive BCLM patients who did not receive HER2targeted therapy after liver metastases had worse outcomes than $\mathrm{HR}+/ \mathrm{HER} 2$ - patients, whereas significantly improved clinical outcomes were observed among those patients undergoing HER2-targeted therapy, in accordance with results from the SEER database. While there was still not a substantial survival advantage of $\mathrm{HR}+1$ HER2- BCLM patients receiving HER2-targeted therapy in the FUSCC dataset, our findings could indicate that HR+/HER2+ or even HR-/HER2+ BCLM patients had a favorable prognosis than HR+/HER2- BCLM patients owing to the introduction of HER2-targeted therapy. The gene that encodes HER2 is amplified and overexpressed in $15-20 \%$ of newly diagnosed breast cancer and results in a worse survival $[38,39]$. Nevertheless, diverse HER2-directed drugs have significantly improved survival in breast cancer patients with HER2-positive subtype [40-45]. Even for HER2positive metastatic breast cancer, antiHER2 therapy also results in considerable and long-lasting improvement in quality of life and overall survival [46]. Furthermore, continuous antiHER2 therapy is of utmost significance for the improvement of survival outcomes in metastatic breast cancer [42, 47, 48]. However, these treatments are expensive and require professional guidance from oncologists, limiting their availability and continuous use for patients without health insurance or in lower income countries, which may explain differences in outcome between these two populations [46]. These inconsistent results on the prognostic role of molecular subtype in BCLM patients may also be explained by differences in baseline characteristics of two groups.

Novel treatment options and different metastatic sites profoundly changed the prognostic value of molecular subtype in breast cancer patients. HR+/HER2- breast cancer were historically considered to have a relatively favorable prognosis, whereas HR+/HER2+ subtype seemed to have the best prognosis and HR+/HER2- and HR-/HER2+ subtype had similar survival among patients with de novo metastatic breast cancer in the HER2-targeted therapy era $[49,50]$. Among breast cancer patients with de novo brain or bone metastases, results were consistent with those in de novo metastatic breast cancer patients $[51,52]$, while HR-/HER2+ subtype had a worse prognosis than the HR+/HER2- subtype among breast cancer patients with de novo lung metastases [53]. Differently, HR-/HER2+ BCLM patients may have a better prognosis than the HR+/HER2- subtype in our study. There are many potential reasons for these discrepancies. HR+/HER2- patients with visceral 
Table 5 Univariate and Multivariate Cox Regression for OS among patients of Breast Cancer with Liver Metastases in the FUSCC dataset

\begin{tabular}{|c|c|c|c|c|}
\hline \multirow[t]{3}{*}{ Variable } & \multicolumn{4}{|l|}{ Overall Survival } \\
\hline & \multicolumn{2}{|l|}{ Univariate } & \multicolumn{2}{|l|}{ Multivariate } \\
\hline & $\mathrm{HR}(95 \% \mathrm{Cl})$ & $P$ Value & $\mathrm{HR}(95 \% \mathrm{Cl})$ & $P$ Value \\
\hline \multicolumn{5}{|l|}{ Age at diagnosis, y } \\
\hline $21-40$ & 1 [Reference] & & 1[Reference] & \\
\hline $41-60$ & $1.34(1.11-1.62)$ & $0.003^{*}$ & $1.38(1.09-1.74)$ & $0.006^{*}$ \\
\hline$>60$ & $1.39(1.10-1.75)$ & $0.005^{*}$ & $1.55(0.86-2.80)$ & 0.145 \\
\hline \multicolumn{5}{|l|}{ Histology } \\
\hline Infiltrating duct carcinoma & 1 [Reference] & & 1 [Reference] & \\
\hline Lobular carcinoma & $0.90(0.56-1.43)$ & 0.648 & $0.68(0.41-1.14)$ & 0.146 \\
\hline Other & $0.72(0.60-0.87)$ & $<0.001^{*}$ & $1.05(0.85-1.29)$ & 0.661 \\
\hline \multicolumn{5}{|l|}{ De novo metastatic diseases } \\
\hline No & 1 [Reference] & & 1[Reference] & \\
\hline Yes & $0.40(0.31-0.52)$ & $<0.001^{*}$ & $0.67(0.29-1.52)$ & 0.337 \\
\hline \multicolumn{5}{|l|}{ Surgery of primary site } \\
\hline No surgery & 1[Reference] & & 1[Reference] & \\
\hline Yes & $2.33(1.83-2.98)$ & $<0.001^{*}$ & $1.02(0.50-2.09)$ & 0.947 \\
\hline \multicolumn{5}{|l|}{ Prior Chemotherapy } \\
\hline No & 1 [Reference] & & 1 [Reference] & \\
\hline Yes & $2.56(1.99-3.28)$ & $<0.001^{*}$ & $1.51(0.88-2.60)$ & 0.135 \\
\hline \multicolumn{5}{|l|}{ Prior Radiotherapy } \\
\hline No & 1 [Reference] & & 1 [Reference] & \\
\hline Yes & $1.33(1.17-1.51)$ & $<0.001^{*}$ & $1.20(1.04-1.39)$ & $0.014^{*}$ \\
\hline Unknown & $0.77(0.54-1.08)$ & 0.122 & $0.67(0.45-0.99)$ & $0.046^{*}$ \\
\hline \multicolumn{5}{|l|}{ Recurrent sequence } \\
\hline First liver metastases & 1 [Reference] & & 1 [Reference] & \\
\hline Subsequent liver metastases & $2.16(1.90-2.46)$ & $<0.001^{*}$ & $1.58(1.33-1.87)$ & $<0.001^{*}$ \\
\hline \multicolumn{5}{|c|}{ Extrahepatic metastatic sites to lung, brain, bone and lymph nodes, No } \\
\hline 0 & $1[$ Reference] & & $1[$ Reference] & \\
\hline 1 & $1.54(1.30-1.83)$ & $<0.001^{*}$ & $1.16(0.95-1.41)$ & 0.15 \\
\hline 2 & $2.16(1.80-2.59)$ & $<0.001^{*}$ & $1.56(1.23-1.97)$ & $<0.001^{*}$ \\
\hline 3 & $2.57(2.08-3.18)$ & $<0.001^{*}$ & $2.05(1.51-2.79)$ & $<0.001^{*}$ \\
\hline All 4 & $5.49(3.56-8.47)$ & $<0.001^{*}$ & $4.59(2.42-8.69)$ & $<0.001^{*}$ \\
\hline \multicolumn{5}{|l|}{ Subtype } \\
\hline HR+/HER2- & 1 [Reference] & & 1 [Reference] & \\
\hline HR+/HER2+ & $0.82(0.68-0.98)$ & $0.033^{*}$ & $1.02(0.83-1.25)$ & 0.851 \\
\hline HR-/HER2+ & $0.84(0.70-1.01)$ & 0.067 & $1.13(0.92-1.40)$ & 0.242 \\
\hline Triple-negative & $1.83(1.53-2.20)$ & $<0.001^{*}$ & $2.17(1.78-2.63)$ & $<0.001^{*}$ \\
\hline Unknown & $1.11(0.79-1.57)$ & 0.544 & $1.63(1.10-2.43)$ & $0.015^{*}$ \\
\hline
\end{tabular}

Notes: + denotes positive; - denotes negative; *denotes a statistically significant $P$-value; HER2, human epidermal growth factor receptor 2; HR, hormone receptor; Cl confidence interval

metastases are often considered to insensitive to endocrine therapy than those without visceral metastases [54]. In the FALCON study, the median progression-free survival (PFS) in patients receiving fulvestrant $500 \mathrm{mg}$ as first-line treatment with and without visceral disease was 13.8 months and 22.3 months, respectively [55]. M. He et al. found that heterogeneity existed among different visceral metastatic sites, and the median PFS was longer 
Table 6 Multivariate Cox Regression for OS among patients of Breast Cancer Liver Metastases with or without HER2-targeted therapy in the FUSCC dataset

\begin{tabular}{|c|c|c|c|c|}
\hline \multirow[t]{2}{*}{ Variable } & \multicolumn{2}{|c|}{ Overall Survival With HER2-targeted therapy } & \multicolumn{2}{|c|}{ Overall Survival Without HER2-targeted therapy } \\
\hline & $\mathrm{HR}(95 \% \mathrm{Cl})$ & $P$ Value & HR $(95 \% \mathrm{Cl})$ & $P$ Value \\
\hline \multicolumn{5}{|l|}{ Subtype } \\
\hline $\mathrm{HR}+/ \mathrm{HER} 2-$ & 1 [Reference] & & 1 [Reference] & \\
\hline $\mathrm{HR}+/ \mathrm{HER} 2+$ & $0.74(0.58-0.95)$ & $0.017^{*}$ & $2.62(1.88-3.66)$ & $<0.001^{*}$ \\
\hline HR-/HER2+ & $0.81(0.63-1.05)$ & 0.110 & $3.43(2.29-5.15)$ & $<0.001^{*}$ \\
\hline Triple-negative & $2.17(1.78-2.63)$ & $<0.001^{*}$ & $2.17(1.78-2.63)$ & $<0.001^{*}$ \\
\hline
\end{tabular}

Adjust for other variables

+ denotes positive; - denotes negative; * denotes a statistically significant $P$-value; $H E R 2$ Human epidermal growth factor receptor $2, H R$ Hormone receptor, $C l$ Confidence interval

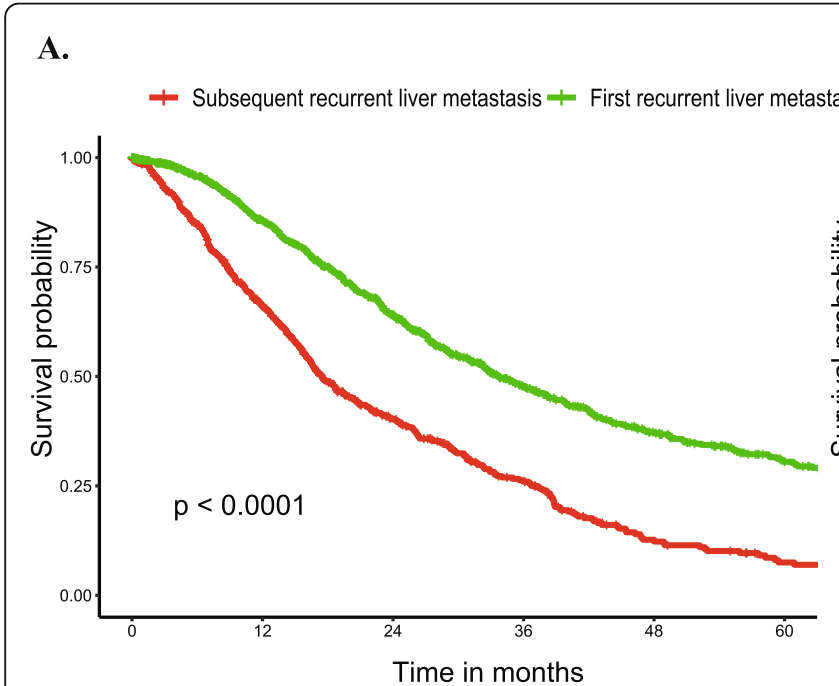

C

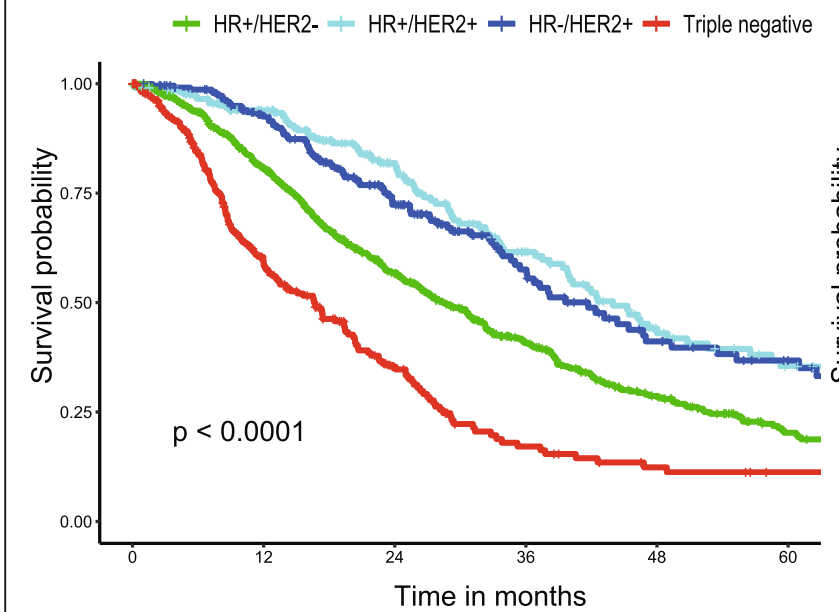

B.

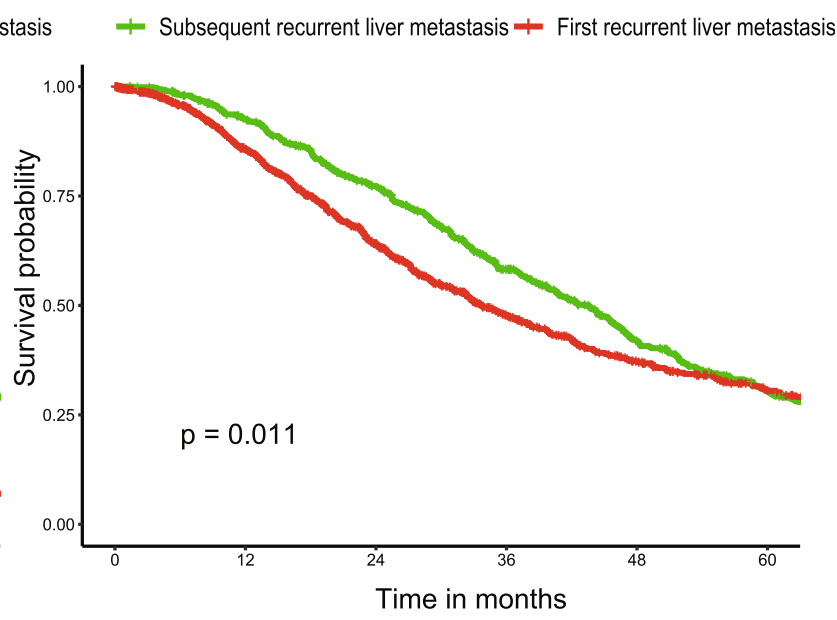

D.

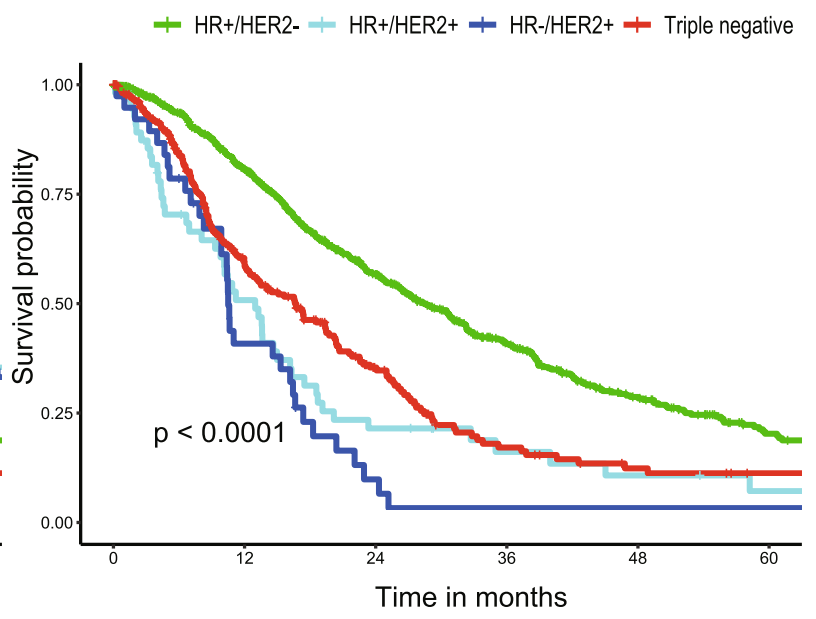

Fig. 2 a Survival stratified by Recurrent sequence (Time from diagnosis of liver metastases). b Survival stratified by Recurrent sequence (Time from metastasis). c Overall Survival Among Patients of Breast Cancer Liver Metastases with targeted therapy stratified by subtype (FUSCC). $\mathbf{d}$ Overall Survival Among Patients of Breast Cancer Liver Metastases without targeted therapy stratified by subtype (FUSCC) 
in patients with lung metastases than in those with liver metastases after fulvestrant therapy (9.6 and 3.7 months, respectively, $P<0.001$ ) [54]. Kimbung et al. also identified a 17-gene liver metastasis-specific signature, which was significantly and independently prognostic for poor relapse-free and overall survival in ER-positive tumors [56]. Fortunately, substantial progress has been made after major advances in our understanding of the biology of ER+/HER2- breast cancer in the past 20 years, such as the development of CDK4/6 inhibitors, mTOR inhibitors, PI $3 \mathrm{~K} \alpha$ inhibitors and histone deacetylase inhibitors [57]. Subgroup analyses suggested that patients with visceral metastases also benefited from the addition of these targeted therapies to endocrine therapy [58-61]. On the basis of the above findings, endocrine therapy combined with these novel targeted therapies may be more appropriate for HR+/HER2- BCLM patients than endocrine therapy alone, but further research is required.

\section{Limitations}

We acknowledge that there are some limitations in our study. First, it was retrospective study including two groups with different baseline characteristics, yielding relatively different results. Second, some detailed information that may have effects on survival was not available, including other metastatic sites, such as the pleura and contralateral breast, number and maximum diameter of liver metastases and performance status. Third, we did not evaluate whether different HER2-targeted therapies, endocrine therapies and surgery on the prognosis of BCLM patients to provide individualized treatment for these specific populations.

\section{Conclusions}

Despite these limitations, our study had a larger sample size and the majority of patients were more recently diagnosed than previous studies on this subject. As a result, our findings may be more reliable and representative. Breast cancer patients with young age, invasive ductal carcinoma, higher pathological grade, and triple-negative and HER2 + subtypes have a high risk of developing liver metastases at initial diagnosis, and therefore deserve more attention during the follow-up. Furthermore, HR+/HER2+ or even HR-/HER2+ BCLM patients had a better prognosis than HR+/HER2- BCLM patients owing to the introduction of HER2-targeted therapy. HER2-targeted based therapy may be the cornerstone of treatment for HER2+ BCLM patients.

\section{Abbreviations}

OS: Overall survival; BCLM: Breast cancer with liver metastases;

SEER: Surveillance, Epidemiology, and End Results; FUSCC: Fudan University Shanghai Cancer Center; HER2: Human epidermal growth factor receptor 2 positive; +: positive; HR: Hormone receptor; HR: Hazard ratio; MBC: Metastatic breast cancer; ER: Estrogen receptor; LM: Liver metastases; IQR: Interquartile range; -: Negative; ORs: Odds ratios; Cls: Confidence intervals;

FGF13: Fibroblast growth factor homologous factor; NETs: Neutrophil extracellular traps; PFS: Progression-free survival

\section{Supplementary Information}

The online version contains supplementary material available at https://doi. org/10.1186/s12885-021-07968-5.

Additional file 1. Figure S1. Selection of patients (SEER).

Additional file 2. Figure S2. Selection of patients (FUSCC).

\section{Acknowledgements}

We acknowledge Xiuzhi Zhu and Yu Gao for collecting data, Zhangru yang and Jianjiao Ni for critically reviewing the manuscript, and Lei Fan and ZhongHua Wang for their leadership and guidance.

\section{Authors' contributions}

$L J$ and LC contributed equally. Study concept and design: LF and ZW; Data collection: $X Z$ and $Y G$; Statistical analysis, or interpretation of data: All authors; Drafting of the manuscript: LJi and LC; Critical revision of the manuscript: LF and ZW; Supervision: LF and ZW. All authors have read and approved the manuscript.

Funding

No funding was received in this study.

Availability of data and materials

The datasets of the present study were available from the corresponding author on reasonable request.

\section{Declarations}

Ethics approval and consent to participate

This study was in accordance with the ethical standards of the Declaration of Helsinki and approved by the Institutional Ethics Review Board of FUSCC. All patients signed written informed consent before this study.

\section{Consent for publication}

Not applicable.

\section{Competing interests}

The authors have declared that no competing interests exist.

\section{Author details}

'Department of Medical Oncology, Fudan University Shanghai Cancer Center, Shanghai, China. ${ }^{2}$ Department of Oncology, Shanghai Medical College, Fudan University, Shanghai, China. ${ }^{3}$ Department of Breast Surgery, Fudan University Shanghai Cancer Center, Shanghai, China.

Received: 6 March 2020 Accepted: 24 February 2021

Published online: 06 March 2021

\section{References}

1. Siegel RL, Miller KD, Jemal A. Cancer statistics, 2019. CA Cancer J Clin. 2019; 69(1):7-34.

2. Miller KD, Nogueira $L$, Mariotto AB, Rowland $J H$, Yabroff $K R$, Alfano $C M$, et al. Cancer treatment and survivorship statistics, 2019. CA Cancer J Clin 2019; 69(5):363-85.

3. Redig AJ, McAllister SS. Breast cancer as a systemic disease: a view of metastasis. J Intern Med. 2013;274(2):113-26.

4. Berman AT, Thukral AD, Hwang WT, Solin LJ, Vapiwala N. Incidence and patterns of distant metastases for patients with early-stage breast cancer after breast conservation treatment. Clin Breast Cancer. 2013;13(2):88-94.

5. Cummings MC, Simpson PT, Reid LE, Jayanthan J, Skerman J, Song S, et al. Metastatic progression of breast cancer: insights from 50 years of autopsies. J Pathol. 2014;232(1):23-31. 
6. Adam R, Aloia T, Krissat J, Bralet MP, Paule B, Giacchetti S, et al. Is liver resection justified for patients with hepatic metastases from breast cancer? Ann Surg. 2006;244(6):897-907 discussion 907-898.

7. Pentheroudakis G, Fountzilas G, Bafaloukos D, Koutsoukou V, Pectasides D, Skarlos D, et al. Metastatic breast cancer with liver metastases: a registry analysis of clinicopathologic, management and outcome characteristics of 500 women. Breast Cancer Res Treat. 2006;97(3):237-44.

8. Adam R, Aloia T, Krissat J, Bralet M-P, Paule B, Giacchetti S, et al. Is liver resection justified for patients with hepatic metastases from breast cancer? Ann Surg. 2006;244(6):897-908.

9. National Comprehensive Cancer Network. (NCCN) clinical practice guidelines in Oncology.Breast cancer, version 2; 2019. https://www.nccn. org/professionals/physician_gls/pdf/breast.pdf

10. Kennecke H, Yerushalmi R, Woods R, Cheang MC, Voduc D, Speers CH, et al. Metastatic behavior of breast cancer subtypes. J Clin Oncol. 2010;28(20): 3271-7.

11. Dent R, Hanna WM, Trudeau M, Rawlinson E, Sun P, Narod SA. Pattern of metastatic spread in triple-negative breast cancer. Breast Cancer Res Treat. 2009;115(2):423-8.

12. Wyld L, Gutteridge E, Pinder SE, James JJ, Chan SY, Cheung KL, et al. Prognostic factors for patients with hepatic metastases from breast cancer. Br J Cancer. 2003;89(2):284-90.

13. Duan XF, Dong NN, Zhang T, Li Q. The prognostic analysis of clinical breast cancer subtypes among patients with liver metastases from breast cancer. Int J Clin Oncol. 2013;18(1):26-32.

14. Xie J, Xu Z. A population-based study on liver metastases in women with newly diagnosed breast cancer. Cancer Epidemiol Biomarkers Prev. 2019; 28(2):283-92.

15. Ge Q-D, Lv N, Kong Y-N, Xie X-H, He N, Xie X-M, et al. Clinical characteristics and survival analysis of breast cancer molecular subtypes with hepatic metastases. Asian Pac J Cancer Prev. 2012;13(10):5081-6.

16. Abbas H, Erridge S, Sodergren MH, Papoulas M, Nawaz A, Menon K, et al. Breast cancer liver metastases in a UK tertiary Centre: outcomes following referral to tumour board meeting. Int J Surg. 2017:44:152-9.

17. Dawood S, Broglio K, Buzdar AU, Hortobagyi GN, Giordano SH. Prognosis of women with metastatic breast cancer by HER2 status and trastuzumab treatment: an institutional-based review. J Clin Oncol. 2010;28(1):92-8.

18. Surveillance, Epidemiology, and End Results Program, Research Data (19752016), National Cancer Institute(NCI), Division of Cancer Control and Population Sciences(DCCPS), Surveillance Research Program(SRP), released April 2019, based on the November 2018 submission [https://seer.cancer. gov/].

19. Sihto H, Lundin J, Lundin M, Lehtimäki T, Ristimäki A, Holli K, et al. Breast cancer biological subtypes and protein expression predict for the preferential distant metastasis sites: a nationwide cohort study. Breast Cancer Res. 2011;13(5):R87.

20. Soni A, Ren Z, Hameed O, Chanda D, Morgan CJ, Siegal GP, et al. Breast cancer subtypes predispose the site of distant metastases. Am J Clin Pathol. 2015;143(4):471-8.

21. van de Water W, Markopoulos C, van de Velde CJH, Seynaeve C, Hasenburg A, Rea D, et al. Association between age at diagnosis and disease-specific mortality among postmenopausal women with hormone receptor-positive breast cancer. JAMA. 2012;307(6):590-7.

22. Purushotham A, Shamil E, Cariati M, Agbaje O, Muhidin A, Gillett C, et al. Age at diagnosis and distant metastasis in breast cancer--a surprising inverse relationship. Eur J Cancer. 2014;50(10):1697-705.

23. Zengel B, Yararbas U, Duran A, Uslu A, Eliyatkin N, Demirkiran MA, et al. Comparison of the clinicopathological features of invasive ductal, invasive lobular, and mixed (invasive ductal + invasive lobular) carcinoma of the breast. Breast Cancer. 2015;22(4):374-81.

24. Zlotnik A, Burkhardt AM, Homey B. Homeostatic chemokine receptors and organ-specific metastasis. Nat Rev Immunol. 2011;11(9):597-606.

25. Li YM, Pan Y, Wei Y, Cheng X, Zhou BP, Tan M, et al. Upregulation of CXCR4 is essential for HER2-mediated tumor metastasis. Cancer Cell. 2004;6(5):45969.

26. Johnstone CN, Pattison AD, Harrison PF, Powell DR, Lock P, Ernst M, et al. FGF13 promotes metastasis of triple-negative breast cancer. Int J Cancer. 2020. https://doi.org/10.1002/ijc.32874.

27. Yang L, Liu Q, Zhang X, Liu X, Zhou B, Chen J, et al. DNA of neutrophil extracellular traps promotes cancer metastasis via CCDC25. Nature. 2020; 583(7814):133-8.
28. Chen W, Hoffmann AD, Liu H, Liu X. Organotropism: new insights into molecular mechanisms of breast cancer metastasis. NPJ Precis Oncol. 2018; 2(1):4.

29. Lindgaard SC, Brinch CM, Jensen BK, Nørgaard HH, Hermann KL, Theile S, et al. Hepatic arterial therapy with oxaliplatin and systemic capecitabine for patients with liver metastases from breast cancer. Breast. 2019;43:113-9.

30. He X, Zhang Q, Feng Y, Li Z, Pan Q, Zhao Y, et al. Resection of liver metastases from breast cancer: a multicentre analysis. Clin Transl Oncol. 2020;22(4):512-21.

31. Ruiz A, Castro-Benitez C, Sebagh M, Giacchetti S, Castro-Santa E, Wicherts DA, et al. Repeat hepatectomy for breast cancer liver metastases. Ann Surg Oncol. 2015;22(Suppl 3):S1057-66.

32. Sadot E, Lee SY, Sofocleous CT, Solomon SB, Gönen M, Peter Kingham T, et al. Hepatic resection or ablation for isolated breast cancer liver metastasis. Ann Surg. 2016;264(1):147-54.

33. Swaminath A, Massey C, Brierley JD, Dinniwell R, Wong R, Kim JJ, et al. Accumulated delivered dose response of stereotactic body radiation therapy for liver metastases. Int J Rad Oncol Biol Phys. 2015;93(3):639-48.

34. Trovo M, Furlan C, Polesel J, Fiorica F, Arcangeli S, Giaj-Levra N, et al. Radical radiation therapy for oligometastatic breast cancer: results of a prospective phase II trial. Radiother Oncol. 2018;126(1):177-80.

35. Brothers JM, Kidwell KM, Brown RK, Henry NL. Incidental radiologic findings at breast cancer diagnosis and likelihood of disease recurrence. Breast Cancer Res Treat. 2016;155(2):395-403.

36. Puglisi F, Follador A, Minisini AM, Cardellino GG, Russo S, Andreetta C, et al. Baseline staging tests after a new diagnosis of breast cancer: further evidence of their limited indications. Ann Oncol. 2005:16(2):263-6.

37. Ravaioli A, Pasini G, Polselli A, Papi M, Tassinari D, Arcangeli V, et al. Staging of breast cancer: new recommended standard procedure. Breast Cancer Res Treat. 2002;72(1):53-60.

38. King CR, Kraus MH, Aaronson SA. Amplification of a novel v-erbB-related gene in a human mammary carcinoma. Science. 1985;229(4717):974-6.

39. Slamon DJ, Clark GM, Wong SG, Levin WJ, Ullrich A, McGuire WL. Human breast cancer: correlation of relapse and survival with amplification of the HER-2/neu oncogene. Science. 1987;235(4785):177-82.

40. Slamon DJ, Leyland-Jones B, Shak S, Fuchs H, Paton V, Bajamonde A, et al. Use of chemotherapy plus a monoclonal antibody against HER2 for metastatic breast cancer that overexpresses HER2. N Engl J Med. 2001; 344(11):783-92.

41. Baselga J, Cortés J, Kim SB, Im SA, Hegg R, Im YH, et al. Pertuzumab plus trastuzumab plus docetaxel for metastatic breast cancer. N Engl J Med. 2012;366(2):109-19.

42. Geyer CE, Forster J, Lindquist D, Chan S, Romieu CG, Pienkowski T, et al. Lapatinib plus capecitabine for HER2-positive advanced breast cancer. N Engl J Med. 2006;355(26):2733-43.

43. Awada A, Colomer R, Inoue K, Bondarenko I, Badwe RA, Demetriou G, et al. Neratinib plus paclitaxel vs Trastuzumab plus paclitaxel in previously untreated metastatic ERBB2-positive breast cancer: the NEfERT-T randomized clinical trial. JAMA Oncol. 2016;2(12):1557-64.

44. Ma F, Ouyang Q, Li W, Jiang Z, Tong Z, Liu Y, et al. Pyrotinib or Lapatinib combined with Capecitabine in HER2-positive metastatic breast cancer with prior Taxanes, Anthracyclines, and/or Trastuzumab: a randomized, phase II study. J Clin Oncol. 2019;37(29):2610-9.

45. Verma S, Miles D, Gianni L, Krop IE, Welslau M, Baselga J, et al. Trastuzumab emtansine for HER2-positive advanced breast cancer. N Engl J Med. 2012; 367(19):1783-91.

46. Hayes DF. HER2 and breast cancer - a phenomenal success story. N Engl J Med. 2019;381(13):1284-6.

47. Bartsch R, Wenzel C, Altorjai G, Pluschnig U, Rudas M, Mader RM, et al. Capecitabine and trastuzumab in heavily pretreated metastatic breast cancer. J Clin Oncol. 2007;25(25):3853-8.

48. von Minckwitz G, du Bois A, Schmidt M, Maass N, Cufer T, de Jongh FE, et al. Trastuzumab beyond progression in human epidermal growth factor receptor 2-positive advanced breast cancer: a german breast group 26/ breast international group 03-05 study. J Clin Oncol. 2009;27(12):1999-2006.

49. Leone JP, Leone J, Zwenger AO, Vallejo CT, Leone BA. Prognostic significance of tumor subtypes in women with breast cancer according to stage: a population-based study. Am J Clin Oncol. 2019;42(7):588-95.

50. Gong Y, Liu YR, Ji P, Hu X, Shao ZM. Impact of molecular subtypes on metastatic breast cancer patients: a SEER population-based study. Sci Rep. $2017 ; 7: 45411$ 
51. Gong Y, Zhang J, Ji P, Ling H, Hu X, Shao ZM. Incidence proportions and prognosis of breast cancer patients with bone metastases at initial diagnosis. Cancer Med. 2018;7(8):4156-69.

52. Martin AM, Cagney DN, Catalano PJ, Warren LE, Bellon JR, Punglia RS, et al. Brain metastases in newly diagnosed breast cancer. JAMA Oncol. 2017;3(8): 1069-77.

53. Xiao W, Zheng S, Liu P, Zou Y, Xie X, Yu P, et al. Risk factors and survival outcomes in patients with breast cancer and lung metastasis: a populationbased study. Cancer Med. 2018;7(3):922-30.

54. He M, Li JJ, Zuo WJ, Ji L, Jiang YZ, Hu XC, et al. Metastatic breast cancer patients with lung or liver metastases should be distinguished before being treated with fulvestrant. Cancer Med. 2019;8(14):6212-20.

55. Robertson JFR, Bondarenko IM, Trishkina E, Dvorkin M, Panasci L, Manikhas A, et al. Fulvestrant $500 \mathrm{mg}$ versus anastrozole $1 \mathrm{mg}$ for hormone receptorpositive advanced breast cancer (FALCON): an international, randomised double-blind, phase 3 trial. Lancet. 2016;388(10063):2997-3005.

56. Kimbung S, Johansson I, Danielsson A, Veerla S, Egyhazi Brage S, Frostvik Stolt M, et al. Transcriptional profiling of breast cancer metastases identifies liver metastasis-selective genes associated with adverse outcome in luminal a primary breast cancer. Clin Cancer Res. 2016;22(1):146-57.

57. Turner NC, Neven P, Loibl S, Andre F. Advances in the treatment of advanced oestrogen-receptor-positive breast cancer. Lancet. 2017; 389(10087):2403-14

58. Turner NC, Finn RS, Martin M, Im SA, DeMichele A, Ettl J, et al. Clinical considerations of the role of palbociclib in the management of advanced breast cancer patients with and without visceral metastases. Ann Oncol. 2018;29(3):669-80

59. Baselga J, Campone M, Piccart M, Burris HA, Rugo HS, Sahmoud T, et al. Everolimus in postmenopausal hormone-receptor-positive advanced breast cancer. N Engl J Med. 2012;366(6):520-9.

60. Andre F, Ciruelos E, Rubovszky G, Campone M, Loibl S, Rugo HS, et al. Alpelisib for PIK3CA-mutated, hormone receptor-positive advanced breast cancer. N Engl J Med. 2019:380(20):1929-40.

61. Jiang Z, Li W, Hu X, Zhang Q, Sun T, Cui S, et al. Tucidinostat plus exemestane for postmenopausal patients with advanced, hormone receptor-positive breast cancer (ACE): a randomised, double-blind, placebocontrolled, phase 3 trial. Lancet Oncol. 2019;20(6):806-15.

\section{Publisher's Note}

Springer Nature remains neutral with regard to jurisdictional claims in published maps and institutional affiliations.

Ready to submit your research? Choose BMC and benefit from:

- fast, convenient online submission

- thorough peer review by experienced researchers in your field

- rapid publication on acceptance

- support for research data, including large and complex data types

- gold Open Access which fosters wider collaboration and increased citations

- maximum visibility for your research: over $100 \mathrm{M}$ website views per year

At $\mathrm{BMC}$, research is always in progress.

Learn more biomedcentral.com/submissions 